\title{
Two new species of the bamboo-feeding planthopper genus Neobelocera Ding \& Yang, 1986 from China (Hemiptera, Fulgoroidea, Delphacidae)
}

\author{
Hong-Xing $\mathrm{LI}^{1}$, Lin YANG ${ }^{2}$ \& Xiang-Sheng CHEN ${ }^{3, *}$ \\ ${ }^{1,2,3}$ Institute of Entomology, Guizhou University, Guiyang, Guizhou 550025, P.R. China. \\ ${ }^{1,2,3}$ The Provincial Special Key Laboratory for Development and Utilization of Insect Resources, \\ Guizhou University, Guiyang, Guizhou 550025, P.R. China. \\ *Corresponding author: chenxs3218@163.com \\ 1Email: 1hx5340@163.com \\ 2Email: yanglin6626@163.com \\ ${ }^{1}$ urn:1sid:zoobank.org:author:A6E7A65E-219F-4B18-B7CB-AB4B9893DE48
${ }^{2}$ urn:1sid:zoobank.org:author:17FAF564-8FDA-4303-8848-346AB8EB7DE4
${ }^{3}$ urn:1sid:zoobank.org:author:D9953BEB-30E6-464A-86F2-F325EA2E4B7C
}

Abstract. Two new species of the bamboo-feeding genus Neobelocera Ding \& Yang, 1986, N. biprocessa sp. nov. and N. russa sp. nov., are described and illustrated from southwest China (Hainan and Guizhou), giving the genus nine species in total. A key is provided to separate all species.

Keywords. Fulgoromorpha, morphology, oriental region, taxonomy.

Li H.-X., Yang L. \& Chen X.-S. 2020. Two new species of the bamboo-feeding planthopper genus Neobelocera Ding \& Yang, 1986 from China (Hemiptera, Fulgoroidea, Delphacidae). European Journal of Taxonomy 641: 1-14. https://doi.org/10.5852/ejt.2020.641

\section{Introduction}

The family Delphacidae Leach, 1815 is the most diverse and cosmopolitan group of the superfamily Fulgoroidea Kirkaldy, 1907, with approximately 2210 described species in 426 genera, of which the vast majority (80\%) belongs to the most species-rich subfamily Delphacinae Muir, 1915 (Urban et al. 2010; Huang et al. 2017; Yu \& Liang 2018; Bourgoin 2019). It is easy to distinguish from all other fulgoroids by the character of a movable spur at the end of the hind tibia (Yang \& Yang 1986). Members of the group feed on the phloem tissues of host plants, and a variety of species are economically significant pests of many important crops, such as rice, maize, wheat, barley, sugarcane and bamboo. Of these species, most incur direct damage to plants through feeding and oviposition (Wilson \& O'Brien 1987; Wilson 2005; Urban et al. 2010). Within the subfamily Delphacinae, 55 species are recognized as economically significant pests, incurring damage to approximately 25 plant crops (Wilson \& O'Brien 1987; Huang et al. 2017). Moreover, approximately 30 delphacid species also serve as vectors of 28 plant pathogens (Wilson \& O'Brien 1987; Wilson 2005; Hogenhout et al. 2008; Urban et al. 2010; Huang et al. 2017). 
The Delphacidae includes six subfamilies: Asiracinae Motschulsky, 1863, Vizcayinae Asche, 1990, Kelisiinae Wagner, 1963, Stenocraninae Wagner, 1963, Plesiodelphacinae Asche, 1985 and Delphacinae (Asche 1985). According to Asche (1985), the Delphacinae are divided into three tribes: Tropidocephalini Muir, 1915, Saccharosydnini Vilbaste, 1968, and Delphacini Leach, 1815.

The genus Neobelocera Ding \& Yang, 1986 (Hemiptera, Auchenorrhyncha, Fulgoroidea, Delphacidae) falls within the tribe Tropidocephalini in the subfamily Delphacinae. Tropidocephalini was erected by Muir (1915) and is the second largest tribe of Delphacinae. Tribal characters are a thickened calcar which is concave on the inner surface and the trailing margin lacks the teeth. The central sperm conducting tube of the membranous aedeagus is within a sclerotized theca. The phallotheca and anal segment are in close functional contact, with the base of the phallotheca mostly integrated into the ventral side of the anal segment. The base of the phallotheca is usually asymmetrically twisted, bearing at least one slender process arising from the base (Asche 1990; Bartlett 2009). Muir (1915) included 6 genera in the tribe when he proposed it as a tribe of the Delphacinae. Asche (1985) increased the number to 21 genera. The tribe currently contains approximately 37 genera and 189 species widely distributed throughout the Palaearctic, Afrotropical, Indomalayan, Australian, Neotropical and Pacific Regions, but most diverse in the Indomalayan Region (Bartlett 2009; Chen \& Tsai 2009; Ren et al. 2014; Huang et al. 2017; Bartlett \& Kennedy 2018; Bourgoin 2019). The New World Tropidocephalini consist of six genera and 20 species, all reported from the South American Neotropics (Bartlett 2009; Bartlett \& Kennedy 2018). The Chinese fauna of Tropidocephalini, comprising about 113 described species in 23 genera, represents the richest species diversity of this tribe worldwide, with most taxa restricted to south China (Chen 2003; Ding 2006; Qin \& Zhang 2010; Hu \& Ding 2013; Ren et al. 2014). Most species of the tribe with reported plant associations feed on bamboo (reported as $78 \%$ by Wilson et al. 1994), with all the remaining associated with other grasses (Chen 2003; Chen \& Tsai 2009; Qin \& Zhang 2010; Bartlett \& Kennedy 2018).

Some species of Arcifrons Ding \& Yang, 1986, Arcofacies Muir, 1915, Bambusiphaga Huang \& Ding, 1979, Epeurysa Matsumura, 1900, Malaxella Ding \& Hu, 1986 and Purohita Distant, 1906 (all from the tribe Tropidocephalini) are important pests of bamboo (Yang et al. 1999; Chen \& Ding 2000; Chen et al. 2000; Chen 2003; Li et al. 2019).

The genus Neobelocera was established by Ding \& Yang (1986) with the type species N. asymmetrica Ding \& Yang, 1986 from Jinghong, Yunnan Province, China. Recently, a taxonomic study of the genus was made by Chen \& Liang (2005) who defined the generic characteristics in detail and provided a key for species identification, distributions and some host plants of known species. Subsequently, the genus and three species, $N$. asymmetrica Ding \& Yang, 1986, N. zhejiangensis (Zhu, 1988), and N. hanyinensis Qin \& Yuan, 1998, were redescribed in a monograph on the Delphacidae of China (Ding 2006). However, both of these works are in Chinese. Later, species of the genus were reviewed again by Hou \& Chen (2010) and the genus was increased to six species. The generic characteristics were redefined. The main morphological characters, male genitalia of six species and female genitalia of three species, were described or redescribed and illustrated (Hou \& Chen 2010). Later, Hu \& Ding (2014) added a species from Tibet, China (N. medogensis Hu \& Ding, 2014) and provided a key. Currently, Neobelocera is only known to occur in China and seven species are described, including $N$. asymmetrica, $N$. zhejiangensis, $N$. hanyinensis, $N$. lanpingensis Chen, 2003, N. laterospina Chen \& Liang, 2005, N. lii Hou \& Chen, 2010 and N. medogensis (Ding et al. 1986; Zhu 1988; Ding \& Hu 1991; Qin \& Yuan 1998; Chen 2003; Chen \& Liang 2005; Hou \& Chen 2010; Hu \& Ding 2014). However, several species of the genus Neobelocera remain unknown and await descriptions.

In this paper, two new species of Neobelocera, $N$. biprocessa sp. nov. and N. russa sp. nov., are described and illustrated from Hainan and Guizhou Provinces, China. A key is provided to separate all species. 


\section{Material and methods}

The morphological terminology follows Hou \& Chen (2010). The standard terminology of venation follows Bourgoin et al. (2015). Dry male specimens were used for the description and illustration. External morphology was observed under a stereoscopic microscope and characters were measured with an ocular micrometer. Color pictures for adult habitus were obtained by the KEYENCE VHX-1000 system. The genital segments of the examined specimens were macerated in $10 \% \mathrm{KOH}$ and drawn from preparations in glycerin jelly using a Leica MZ 12.5 stereo microscope. Illustrations were scanned with a Canon CanoScan LiDE 200 and imported into Adobe Photoshop 6.0 for labeling and plate composition.

The type specimens of the new species are deposited in the Institute of Entomology, Guizhou University, Guiyang, China (GUGC).

\section{Results}

Order Hemiptera Linnaeus, 1758

Infraorder Fulgoromorpha Evans, 1946

Family Delphacidae Leach, 1815

Subfamily Delphacinae Muir, 1915

Tribe Tropidocephalini Muir, 1915

Genus Neobelocera Ding \& Yang, 1986

Type species: Neobelocera asymmetrica Ding \& Yang, 1986 (original designation).

\section{Diagnosis}

The genus Neobelocera is easily distinguished from other genera of Tropidocephalini by the following combination of characters: antennae with first segment subsagittate, markedly flattened, a longitudinal carina down middle, the ventral apical angle longer than dorsal apical angle (Figs 1E, 2B, 3E, 4B); when postclypeus viewed in profile, apical part of median carina bent at rounded angle, not at right angle (Figs 1D, 3D) (Hou \& Chen 2010; Hu \& Ding 2014).

\section{Host plant}

Bamboo.

\section{Distribution}

Oriental region (China).

Key to species (males) of Neobelocera Ding \& Yang, 1986 (revised from Hu \& Ding 2014)

1. Forewings yellowish white, hyaline, with a small dark brown marking on furcation of $\mathrm{ScP}(\mathrm{Hu} \&$ Ding 2014: fig. 10) .... N. medogensis Hu \& Ding, 2014

- Forewings with blackish brown marking, of which veins with white spots or white short stripes at intervals (Figs 1F, 3F) ....

2. Frons with pale transverse band below level of lower margin of eyes (Figs 1E, 2B, 3E, 4B) ........ 3

- Frons without transverse band (Chen \& Liang 2005: fig. 10) ........................................................ 6

3. Ventral margin of pygofer with 3 medioventral processes (Fig. 4D) …......................................... 4

- Ventral margin of pygofer concave medially, without process (Fig. 2F) ………………………... 5 
4. Frons with some short, yellowish white transverse stripes subapically; genae with 2-3 light brown spots (Fig. 3E); pygofer with medioventral processes short, median one slightly longer than lateral ones (Fig. 4D)

N. russa sp. nov.

- Frons without yellowish white transverse stripe subapically; genae without light brown spot (Chen 2003: fig. 3); medioventral processes of pygofer with median one short, lateral ones very slender and long (Chen 2003: fig. 4)

N. lanpingensis Chen, 2003

5. Phallus with basal half broad, compressed, apical half slender, tubular, acute at apex, with process at basal $1 / 3$ and node subapically; phallobase with long straight spinous process basally and three processes apically (Fig. 2G)

N. biprocessa sp. nov.

- Phallus slender, tubular, rounded at apex, without process and node; phallobase slender, without process (Ding et al. 1986: figs 6-4) N. asymmetrica Ding \& Yang, 1986

6. Median carina of vertex, pronotum, mesonotum and frons white bordered with dark brown to blackish brown (Chen \& Liang 2005: figs 9-10)

- Not as above, forewings at basal part and hind margin of apical part with blackish brown markings (Hou \& Chen 2010: fig. 19); ventral margin of pygofer concave medially, lateral side of which each with a short process (Hou \& Chen 2010: fig. 24) N. lii Hou \& Chen, 2010

7. Pygofer with ventral margin concave medially, on lateral side each with a long, slender process (Chen \& Liang 2005: fig. 12); genital styles slender and long, with a spine-like process subapically (Chen \& Liang 2005: figs 15-16)

N. laterospina Chen \& Liang, 2005

- Pygofer with ventral margin without any process (Qin \& Yuan 1998: fig. 1D)

8. Genital styles long, parallel and slightly sinuate, with inner apical angle acute, without process (Ding 2006: fig. 100C)

N. zhejiangensis (Zhu, 1988)

- Genital styles rather robust, apex acute, with branch lateral process terminating with 3-5 spinose processes (Qin \& Yuan 1998: fig. 1F-G)

N. hanyinensis Qin \& Yuan, 1998

Neobelocera lanpingensis Chen, 2003

Neobelocera lanpingensis Chen, 2003: 2, figs 1-8.

Neobelocera lanpingensis - Hou \& Chen 2010: 44, figs 1-8.

Material examined

Holotype

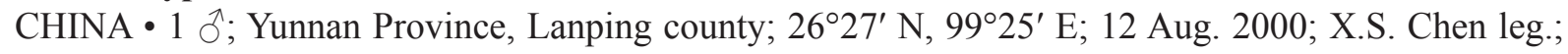
GUGC-FS-TN-20000801.

\section{Paratypes}

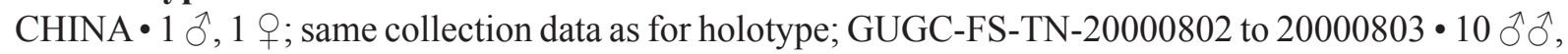
4 우; Guizhou Province, Weining County; $27^{\circ} 04^{\prime}$ N, $104^{\circ} 07^{\prime}$ E; 4 Aug. 2017; H.X. Li, J. Wang, Q. Luo and N. Gong leg.; on bamboo; GUGC-FS-TN-20170801 to 20170814.

\section{Host plant}

Bamboo.

\section{Distribution}

China (Yunnan, Guizhou). 


\section{Remark}

This species was described from Yunnan Province, China based on two male and one female specimens deposited in GUGC by X.S. Chen (2003). This species is here recorded from Guizhou Province, China for the first time.

Neobelocera biprocessa sp. nov.

urn:1sid:zoobank.org:act:ADB55E92-788F-4CEA-AC25-7E35035028B2

Figs $1-2$

\section{Diagnosis}

The salient features of the new species include the following: frons with pale transverse band below level of lower margin of eyes (Fig. 2B); antennal segment I subsagittate, markedly flattened, with median longitudinal carina, the ventral apical angle longer than dorsal apical angle (Fig. 2B); ventral margin
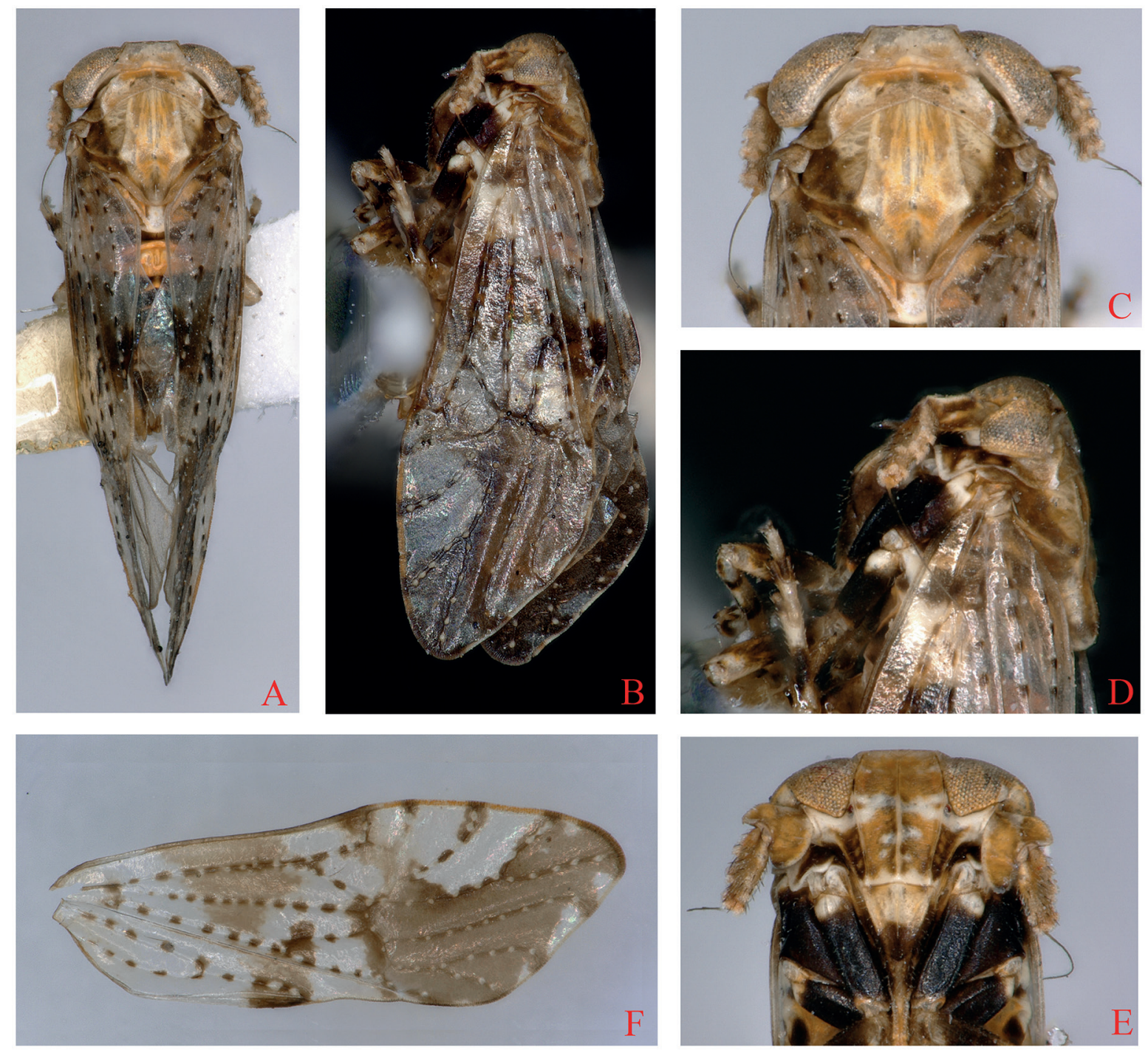

Fig. 1. Neobelocera biprocessa sp. nov., holotype (GUGC-FS-TN-20090401) A. Male habitus, dorsal view. B. Same, lateral view. C. Head and thorax, dorsal view. D. Same, lateral view. E. Face. F. Forewing. 
of pygofer concave U-shape, without process (Fig. 2F); phallus with basal half broad, compressed, apical half slender, tubular, curved ventrally, acute at apex, with spinous process at basal $1 / 3$ and node subapically (Fig. 2G); phallobase with long straight spinous process basally and three processes apically (Fig. 2G); genital styles in posterior view inner margin with two processes (Fig. 2H).

\section{Etymology}

The species epithet is derived from the Latin words ' $b i$-' and 'process', referring to the inner margin of genital styles with two processes.

\section{Type material}

\section{Holotype}

CHINA • ${ }^{\wedge}$; Hainan Province, Changjiang County; $1^{\circ} 06^{\prime}$ N, 10904' E; 24 Apr. 2009; X.H. Hou leg.; on bamboo; GUGC-FS-TN-20090401.
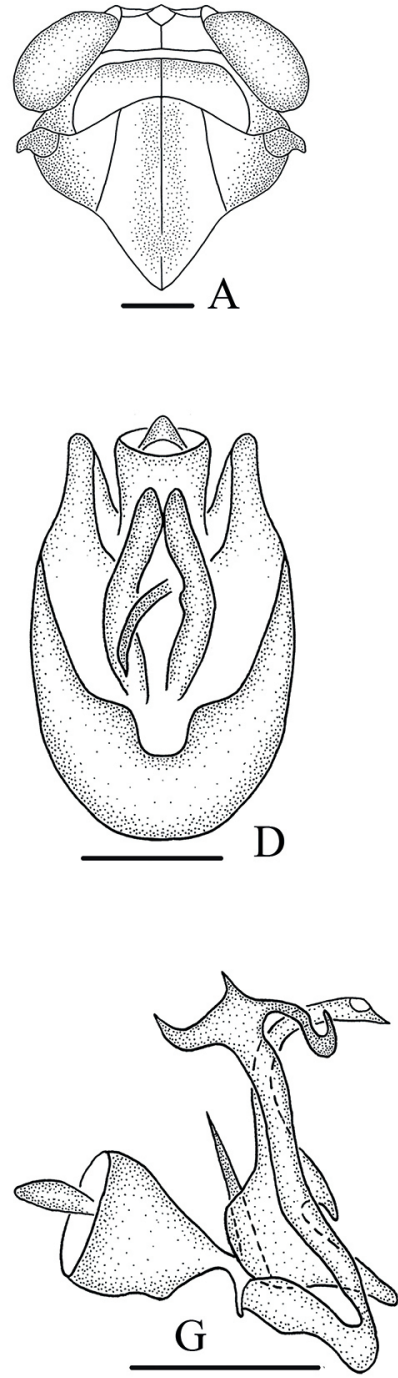
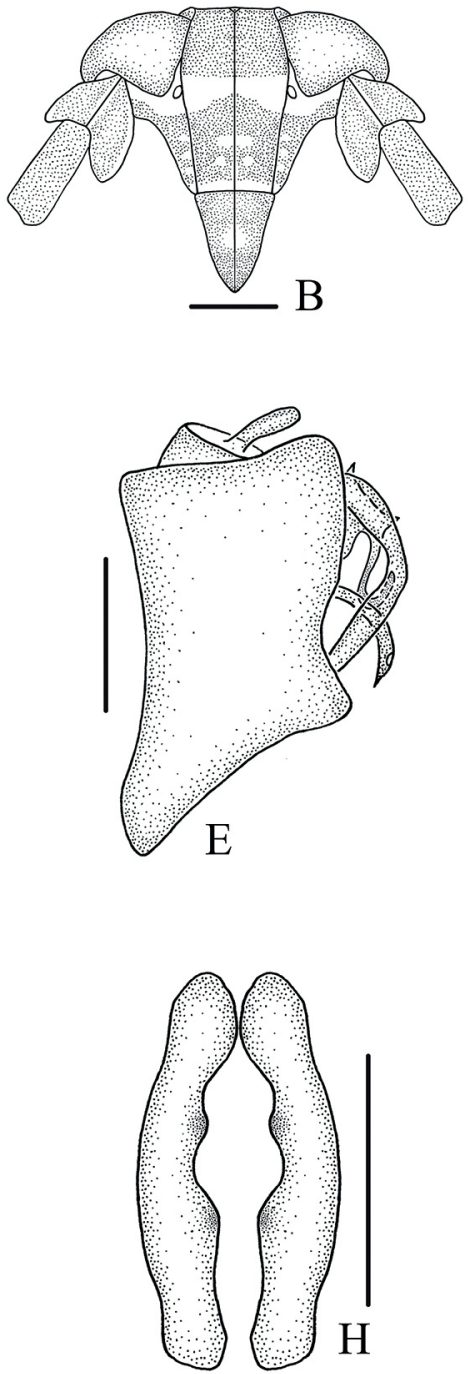
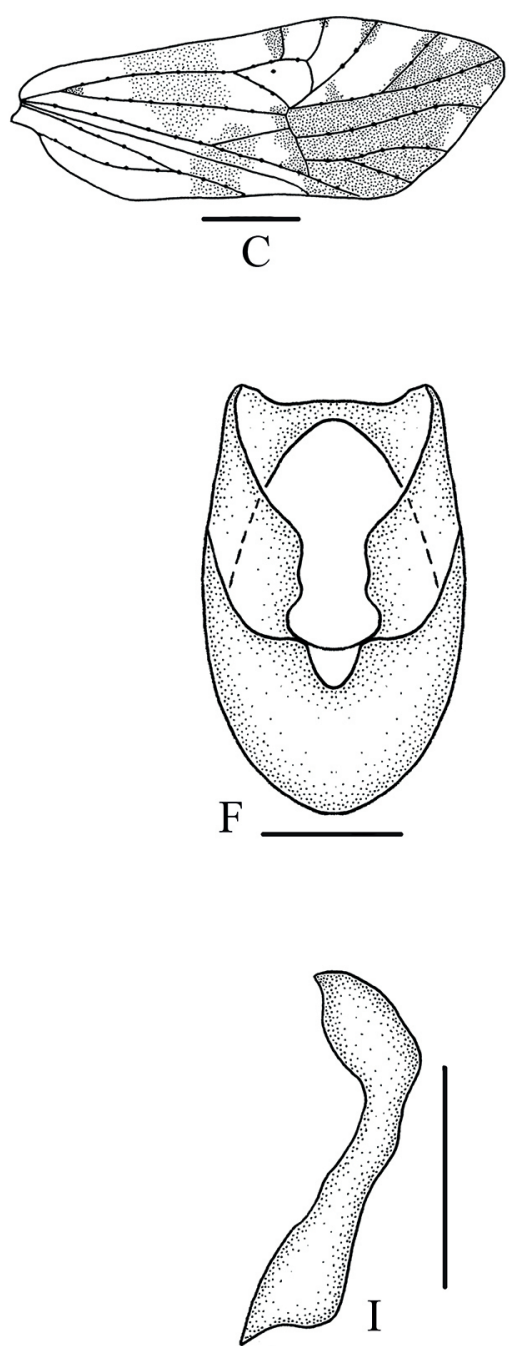

Fig. 2. Neobelocera biprocessa sp. nov., holotype (GUGC-FS-TN-20090401). A. Head and thorax, dorsal view. B. Face. C. Forewing. D. Male genitalia, posterior view. E. Same, lateral view. F. Pygofer, posterior view. G. Anal segment and aedeagus, lateral view. H. Genital style, posterior view. I. Same, lateral view. Scale bars: A-B, D-I $=0.2 \mathrm{~mm}$; C $=0.5 \mathrm{~mm}$. 


\section{Paratypes}

CHINA • 1 §ิ, 2 우우 same collection data as for holotype; GUGC-FS-TN-20090402 to 20090404.

\section{Description}

Measurements. Body length including forewing: male 2.8-2.9 $\mathrm{mm}(\mathrm{N}=2)$; female 3.0-3.1 mm $(\mathrm{N}=2)$; forewing length: male $2.5 \mathrm{~mm}(\mathrm{~N}=2)$; female $2.6-2.7 \mathrm{~mm}(\mathrm{~N}=2)$.

Coloration. General coloration yellowish white to brown (Fig. 1A-F). Vertex, pronotum, mesonotum yellowish white, pronotum and mesonotum with lateral areas brown, base of pronotum, middle areas of mesonotum somewhat light yellow (Figs 1C, 2A). Frons and genae yellowish brown, except broad transversal stripe below level of lower margin of eyes and narrow stripe of apex yellowish white, along near apex of median carina of frons and inner margin of lateral carinae of genae with several short transversal stripes, yellowish white. Clypeus with basal half yellowish white and apical half dark brown (Fig. 1E). Rostrum yellowish brown, except apex dark brown. Eyes yellowish brown. Ocelli reddish brown. Antennae brown, except lateral margins of first segment yellowish white (Fig. 1E). Legs yellowish white to brown, with dark maculations. Forewing light yellowish white, almost hyaline, basal part near costal margin with big infuscate markings, and apical part from transverse veins to apex with dark brown markings, veins with white spots (Fig. 1F). Wings hyaline with veins dark brown.

HEAD AND thORAX. Head including eyes wider than pronotum (Fig. 2A). Vertex broad transversely, wider at base than long medially about 3.80: 1 (Fig. 2A). Frons in middle line longer than wide at widest part about 1.46: 1, widest above level of lower margin of eyes (Fig. 2B). Postclypeus at base almost as wide as frons at apex (Fig. 2B). Antennae with first segment shorter than second segment about 0.53: 1, second segment cylindrical, longer than wide about 2.80: 1 (Fig. 2B). Pronotum subequal to vertex medially. Mesonotum longer than vertex and pronotum combined about 2.27: 1 (Fig. 2A). Forewing in middle line longer than wide at widest part about 2.73: 1 (Fig. 2C).

Male genitalia. Anal segment small, ring-like (Fig. 2D). Pygofer in profile much longer ventrally than dorsally (Fig. 2E), in posterior view with opening longer than wide, ventral margin concave U-shape, without process (Fig. 2F). Aedeagus with phallobase, phallus with basal half broad, compressed, apical half slender, tubular, curved ventrally, acute at apex, with spinous process at basal $1 / 3$ ventrally and node subapically, phallobase long, arising from base of aedeagus, curved at basal 1/3, 7-shaped, with long straight spinous process basally and three processes apically (Fig. 2G). Genital styles simple, long, inner margin with two processes (Fig. 2H).

\section{Host plant}

Bamboo.

\section{Distribution}

China (Hainan).

\section{Remarks}

This new species is assigned to the genus Neobelocera because the antennal segment I is subsagittate, markedly flattened, with a median longitudinal carina, the ventral apical angle longer than the dorsal apical angle (Fig. 2B). This species is similar to N. asymmetrica Ding \& Yang, 1986 in having the vertex short relatively (Fig. 2A), forewing broad and about 2.7 times as broad as median length, apical margin acutely rounded, with blackish brown markings, and veins with white spots or white short stripes at intervals (Fig. 1F), frons with broad transversal stripe below level of lower margin of eyes yellowish white, along near apex of median carina with several short transversal stripes, yellowish white (Fig. 1E), 
genae with 2-3 light brown spots (Fig. 1E), male pygofer with ventral margin concave U-shape, without process (Fig. 2F). However, it can be distinguished from the latter by the following features: (1) phallus (Fig. 2G) with basal half broad, compressed, apical half slender, tubular, curved ventrally, acute at apex, with process at basal $1 / 3$ and node subapically (in $N$. asymmetrica, phallus tubular, rounded at apex, without process and node); (2) phallobase (Fig. 2G) curved at basal 1/3, 7-shaped, with long straight spinous process basally and three processes apically (in $N$. asymmetrica, phallobase slender, long and curly, spine-like); (3) genital styles (Fig. 2H) in posterior view inner margin with small processes medially and at basal $1 / 3$ (in $N$. asymmetrica, genital styles in posterior view inner margin without process medially, with a nipple-like process at subapical $1 / 3$ ).

\section{Neobelocera russa sp. nov. urn:lsid:zoobank.org:act:9D61BFF2-91B3-4BF5-92C4-DBB1C5E5ED8E}

Figs 3-4

\section{Diagnosis}

The salient features of the new species include the following: frons brown, except broad transversal stripe between ocelli and narrow stripe at apex yellowish white, along near apex of median carina with several short transversal stripes, yellowish white (Fig. 3E); genae with 2-3 light brown spots (Fig. 3E); antennal segment I subsagittate, markedly flattened, with median longitudinal carina, the ventral apical angle longer than dorsal apical angle (Fig. 4B); ventral margin of pygofer with 3 medioventral processes short, median one slightly longer than lateral ones (Fig. 4D); genital styles swollen subapically (Fig. 4H).

\section{Etymology}

The species epithet is derived from the Latin word 'russa', referring to the body with rust color.

\section{Type material}

\section{Holotype}

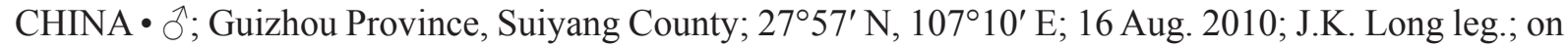
bamboo; GUGC-FS-TN-20100801.

\section{Paratypes}

CHINA • 3 つðં; same collection data as for holotype; GUGC-FS-TN-20100802 to 20100804.

\section{Description}

MEASUREMENTS. Body length including forewing: male 4.0-4.3 $\mathrm{mm}(\mathrm{N}=3)$; forewing length: male $3.6-3.7 \mathrm{~mm}(\mathrm{~N}=3)$.

Coloration. General coloration dark yellowish brown (Fig. 3A-F). Vertex, pronotum, mesonotum dirty yellowish brown, except Y-shaped carina of vertex, all carinae of pronotum and mesonotum yellowish white (Fig. 3C). Frons and genae brown, except broad transversal stripe below level of lower margin of eyes and narrow stripe of apex yellowish white, along near apex of median carina of frons and inner margin of lateral carinae of genae with several short transversal stripes, yellowish white. Clypeus yellowish brown to brown (Fig. 3E). Eyes dirty yellowish brown. Ocelli reddish brown. Antennae brown, except lateral margins of first segment yellowish white (Fig. 3E). Legs yellowish white, with dark brown maculations. Forewing light yellowish white, almost hyaline, basal part near costal margin with big infuscate markings, and apical part from transverse veins to apex with dark brown markings, veins with white spots (Fig. 3F). Wings hyaline with veins dark brown. 
HeAd AND thorax. Head including eyes almost as wide as pronotum (Fig. 4A). Vertex wider at base than long medially about 2.57: 1 (Fig. 4A). Frons in middle line longer than wide at widest part about 1.74: 1, widest above level of lower margin of eyes. Postclypeus at base almost as wide as frons at apex (Fig. 4B). Antennae with first segment shorter than second segment about 0.65: 1, second segment cylindrical, longer than wide about 2.80: 1 (Fig. 4B). Pronotum subequal to vertex medially. Mesonotum longer than vertex and pronotum combined about 2.25: 1 (Fig. 4A). Forewing longer in middle line than wide at widest part about 3.25: 1 (Fig. 4C).

Male genitalia. Anal segment small, ring-like (Fig. 4D). Pygofer in profile much longer ventrally than dorsally (Fig. 4E), in posterior view with opening longer than wide, ventral margin with three medioventral processes, median one longer than lateral ones, truncate apically, lateral ones stout, tapering (Fig. 4D). Aedeagus (Fig. 4F-G) with phallobase, phallus tubular, bent ventrad medially, with node at apex, middle dorsal with a spinous process, directed dorsad, apex with 2 long spinous processes. In addition, 2 processes at subapical part of phallus, right one strongly curved. Phallobase
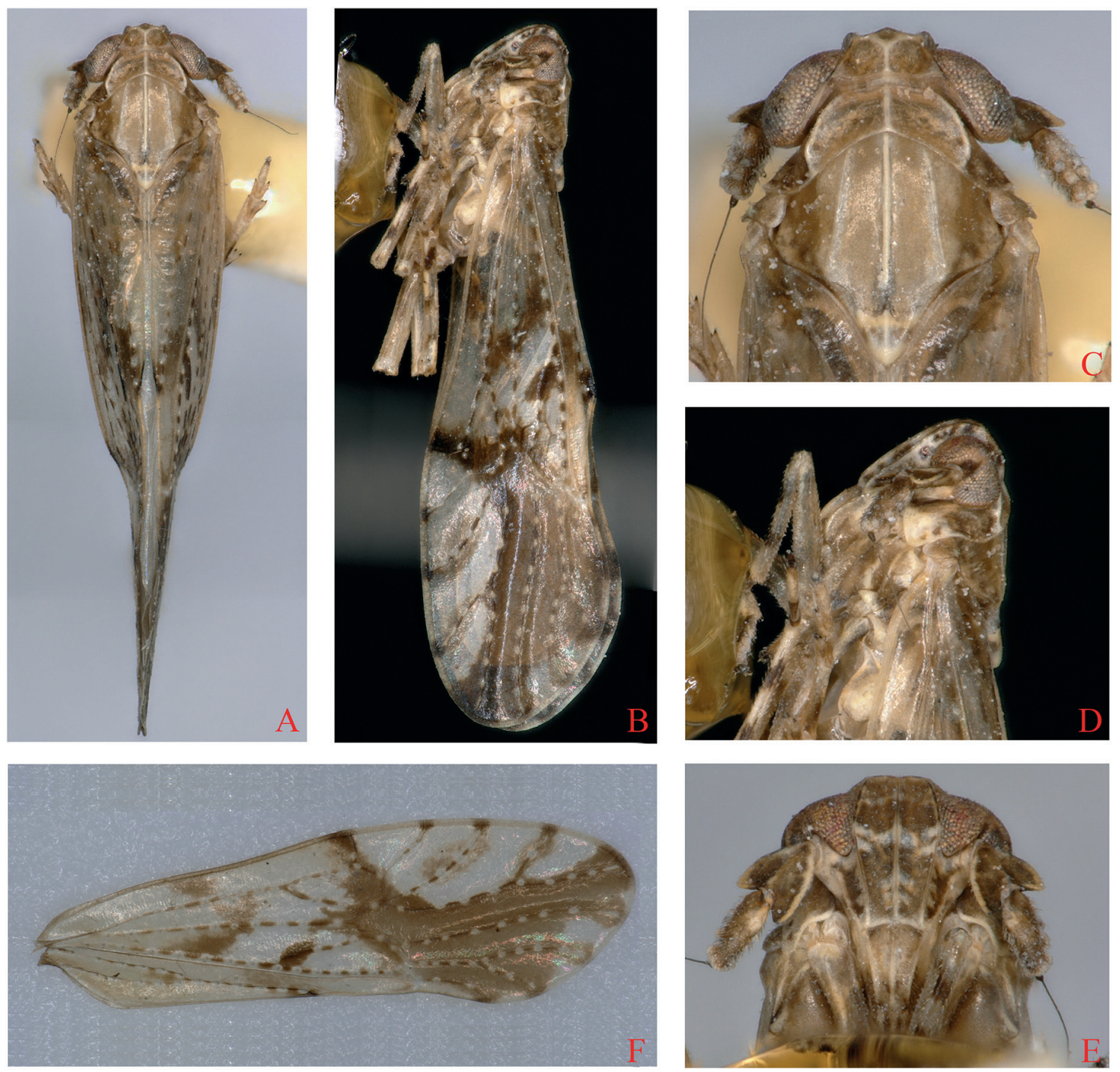

Fig. 3. Neobelocera russa sp. nov., holotype (GUGC-FS-TN-20100801). A. Male habitus, dorsal view. B. Same, lateral view. C. Head and thorax, dorsal view. D. Same, lateral view. E. Face. F. Forewing. 
slender, tubular, arising from base of aedeagus, running dorsad, then curving caudad, after median part, turned left then ventrad, tapering apically. Genital styles simple, long, reaching to ventral margin of anal segment, swollen subapically (Fig. 4H).

\section{Host plant}

Bamboo.

\section{Distribution}

China (Guizhou).
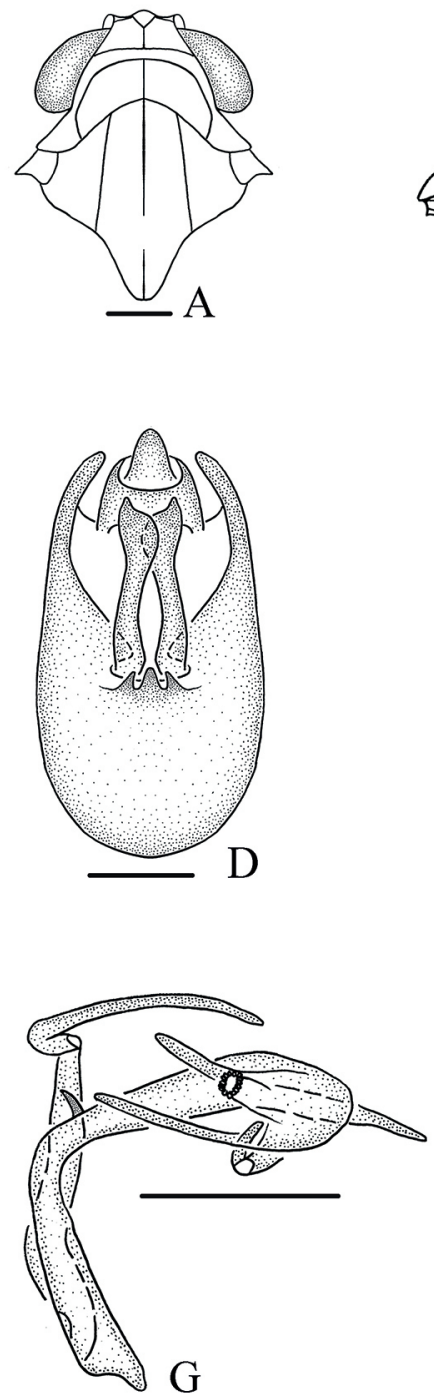
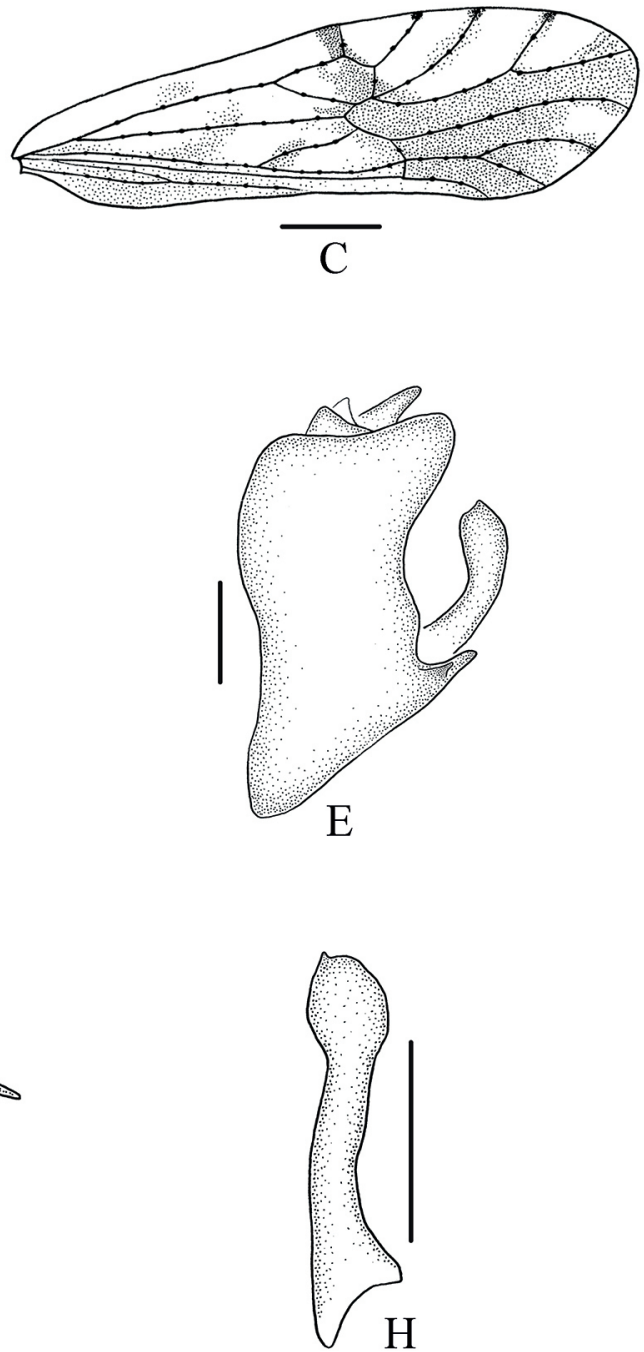
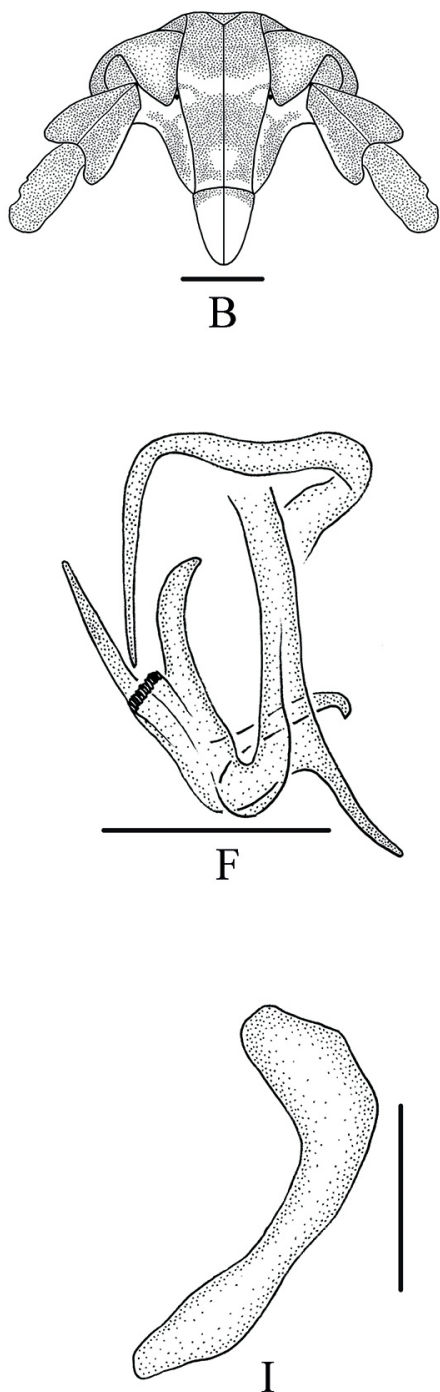

Fig. 4. Neobelocera russa sp. nov., holotype (GUGC-FS-TN-20100801). A. Head and thorax, dorsal view. B. Face. C. Forewing. D. Male genitalia, posterior view. E. Same, lateral view. F. Aedeagus, posterior view. G. Same, lateral view. H. Genital style, posterior view. I. Same, lateral view. Scale bars: A-B, D-I $=0.2 \mathrm{~mm} ; \mathrm{C}=0.5 \mathrm{~mm}$. 


\section{Remarks}

This new species is assigned to the genus Neobelocera because the antennal segment I is subsagittate, markedly flattened, with a median longitudinal carina, the ventral apical angle longer than dorsal apical angle (Fig. 4B). This species is similar to $N$. lanpingensis Chen, 2003 in having the body elongate (Fig. 3A-B), forewings long and narrow, apex oblique and tapering, with blackish brown markings, and with white spots or white short stripes at intervals (Fig. 3F), frons with pale transverse band below level of lower margin of eyes (Fig. 3E), male pygofer with medioventral processes (Fig. 4D), phallus with four spinous processes at apex and near apex, phallobase slender and long (Fig. 4F-G). However, it can be distinguished from the latter by the following features: (1) frons (Fig. 3E) along near apex of median carina with several short transversal stripes, yellowish white (in $N$. lanpingensis, frons without yellowish white transverse stripes subapically); (2) genae (Fig. 3E) with 2-3 light brown spots (in N. lanpingensis, genae without light brown spot); (3) medioventral processes of pygofer (Fig. 4D) with median one longer than lateral ones, truncate apically, lateral ones stout, tapering (in N. lanpingensis, medioventral processes with median one short, tapering, lateral ones very slender, long, sinuate); (4) genital styles (Fig. 4H) swollen subapically (in N. lanpingensis, genital styles tapering apically).

\section{Discussion}

Our species-level review of Neobelocera based on morphology increased the species-richness of the genus by two species named and described above. Despite the fact that species of Neobelocera are quite similar in appearance, the structure of male genitalia is varied. For example, $N$. biprocessa sp. nov. and $N$. russa sp. nov. are easily distinguished from the other species in the genus based on the shape of the aedeagus and the genital styles, but the male genitalia of these two species and the rest of the species in the genus are homogenous.

Of the genera of the tribe Tropidocephalini, only three, Bambucibatus Muir, 1915, Belocera Muir, 1913 and Neobelocera, have the antennae flattened, sagittate or subsagittate. However, these three genera are substantially different and the differences were discussed by Hou \& Chen (2010).

The phylogenetic work of Huang et al. (2017), obtained from a maximum likelihood analysis of four genes (cox1, cytb, 16S rDNA and 28S rDNA), places Neobelocera (using Neobelocera sp.) as sister to a clade of Arcofaciella Fennah, 1956, Tropidocephala Stål, 1853, Carinofrons Chen \& Li, 2000, and Epeurysa Matsumura, 1900. The monophyly of Neobelocera was supported. Nevertheless, the lack of DNA sequence data for the rest of the species in the genus Neobelocera hinders further investigation of their taxonomic status as well as their relationships to determine pairs of sister taxa. Additional work remains to be done on the genus, such as a molecular phylogenetic analysis.

Although the host plant of two species, Neobelocera hanyinensis and N. medogensis, are still unknown, most of species in the genus Neobelocera were found to feed exclusively on bamboo (Poaceae, Bambusoideae) (Ding et al. 1986; Zhu 1988; Ding \& Hu 1991; Chen 2003; Chen \& Liang 2005; Hou \& Chen 2010). China is one of the world's bamboo center production areas, with more than 500 species of bamboo plants in total. Up to now, nine species of Neobelocera have been reported from China. However, some species remain unknown and await descriptions.

\section{Acknowledgements}

The authors are grateful to collectors for collecting specimens. This work is supported by the National Natural Science Foundation of China (No. 31472033, 31160163), the Program of Science and Technology Innovation Talents Team, Guizhou Province (No. 20144001), the Program of Excellent Innovation Talents, Guizhou Province (No. 20154021), and the Youth Science and Technology Talent Development Project in the Education Department of Guizhou Province (Grant No. qianjiaohe KY zi [2017]103). 


\section{References}

Asche M. 1985. Zur Phylogenie der Delphacidae Leach, 1815 (Homoptera: Cicadina: Fulgoromorpha). Marburger Entomologische Publikationen 2 (1-2): 1-912.

Bartlett C.R. 2009. A new genus of new world Tropidocephalini (Hemiptera: Delphacidae: Delphacinae), with the description of two new species. Entomological News 120 (4): 387-396. https://dx.doi.org/10.3157/021.120.0407

Bartlett C.R. \& Kennedy A.C. 2018. A review of New World Malaxa (Hemiptera: Fulgoroidea: Delphacidae). Zootaxa 4441 (3): 511-528. https://doi.org/10.11646/zootaxa.4441.3.5

Bourgoin T., Wang R.R., Asche M., Hoch H., Soulier-Perkins A., Stroinski A., Yap S. \& Szwedo J. 2015. From micropterism to hyperpterism: recognition strategy and standardized homology-driven terminology of the forewing venation patterns in planthoppers (Hemiptera: Fulgoromorpha). Zoomorphology 134 (1): 63-77. https://doi.org/10.1007/s00435-014-0243-6

Bourgoin T. 2019. FLOW (Fulgoromorpha Lists on the Web): a world knowledge base dedicated to Fulgoromorpha. Available from http://hemipteradatabasesorg/flow [accessed 4 Sep. 2019].

Chen X.S. \& Ding J.H. 2000. Description of a new species of the genus Epeurysa from China (Homoptera: Delphacidae). Acta Zootaxonomica Sinica 25: 413-425.

Chen X.S., Li Z.Z. \& Jiang S.N. 2000. Descriptions of two new species of Delphacidae attacking bamboo from China (Homoptera: Fulgoroidea). Scientia Silvae Sinicae 36 (3): 77-80.

Chen X.S. 2003. A new species of the genus Neobelocera (Homoptera: Delphacidae) from China. Zootaxa 290: 1-4.

Chen X.S. \& Liang A.P. 2005. A taxonomic study of the genus Neobelocera (Homoptera, Fulgoroidae, Delphacidae). Acta Entomologica Sinica 30: 374-378.

Chen X.S. \& Tsai J.H. 2009. Two new genera of Tropidocephalini (Hemiptera: Fulgoroidea: Delphacidae). Florida Entomologist 92 (2): 261-268. https://doi.org/10.1653/024.092.0210

Ding J.H., Yang L.F. \& Hu C.L. 1986. Descriptions of new genera and species of Delphacidae attacking bamboo from Yunnan Province, China. Acta Entomologica Sinica 29 (4): 415-423. https://doi.org/10.16380/j.kcxb.1986.04.016

Ding J.H. \& Hu C.L. 1991. Notes on male Neobelocera zhejiangensis (Zhu) comb. nov. (Homoptera: Delphacidae). Acta Entomologica Sinica 34: 250.

Ding J.H. 2006. Fauna Sinica Insecta Vol. 45 Homoptera Delphacidae. Science Press, Beijing.

Hou X.H. \& Chen X.S. 2010. Review of the Oriental bamboo delphacid genus Neobelocera Ding \& Yang (Hemiptera: Fulgoromorpha: Delphacidae) with the description of one new species. Zootaxa 2387: $39-50$.

Hu C.L. \& Ding J.H. 2013. One new genus and species of Tropidocephalini (Hemiptera, Delphacidae, Delphacinae) from Tibet, China. Acta Zootaxonomica Sinica 38 (3): 552-555.

Hu C.L. \& Ding J.H. 2014. A new species of Neobelocera Ding \& Yang (Hemiptera: Delphacidae: Delphacinae: Tropidocephalini) from China, with a key to species of the genus. Zootaxa 3784 (2): 196199. https://doi.org/10.11646/zootaxa.3784.2.9

Huang Y.X., Zhang L.F., Bartlett C.R. \& Qin D.Z. 2017. Resolving phylogenetic relationships of Delphacini and Tropidocephalini (Hemiptera: Delphacidae: Delphacinae) as inferred from four genetic loci. Scientific Reports 7 (3319): 1-10. https://doi.org/10.1038/s41598-017-03624-w 
Hogenhout S.A., Ammar E.D., Whitfield A.E. \& Redinbaugh M.G. 2008. Insect vector interactions with persistently transmitted viruses. Annual Review of Phytopathology 46: 327-359.

https://doi.org/10.1146/annurev.phyto.022508.092135

Li H.X., Yang L. \& Chen X.S. 2019. Two new species of the bamboo-feeding planthopper genus Purohita Distant from China (Hemiptera, Fulgoromorpha, Delphacidae). ZooKeys 855: 85-94.

https://doi.org/10.3897/zookeys.855.31561

Muir F. 1915. A contribution towards the taxonomy of the Delphacidae. The Canadian Entomologist 47: 317-320.

Qing D.Z. \& Yuan F. 1998. A new species of the genus Neobelocera (Homoptera: Delphacidae). Entomotaxonomia 20 (3): 168-170.

Qin D.Z. \& Zhang Y.L. 2010. A key to the genera of Tropidocephalini (Hemiptera: Fulgoromorpha: Delphacidae) of China with description of Mucillnata rava, new genus and species. Zootaxa 2448: 61-68.

Ren F.J., Zheng L.F., Huang Y.X. \& Qin D.Z. 2014. Lauriana Ren \& Qin, a new genus of the tribe Tropidocephalini (Hemiptera: Fulgoromorpha: Delphacidae) from China. Zootaxa 3784: 84-88. https://doi.org/10.11646/zootaxa.3784.1.6

Urban J.M., Bartlett C.R. \& Cryan J.R. 2010. Evolution of Delphacidae (Hemiptera: Fulgoroidea): combined-evidence phylogenetics reveals importance of grass host shifts. Systematic Entomology 35: 678-691. https://doi.org/10.1111/j.1365-3113.2010.00539.x

Wilson S.W. \& O'Brien L.B. 1987. A survey of planthopper pests of economically important plants (Homoptera: Fulgoroidea). In: Wilson M.R. \& Nault L. (eds) Proceedings of the 2nd International Workshop on Leafhoppers and Planthoppers of Economic Importance: 343-360. CAB International Institute of Entomology. Queens Gate, London.

Wilson S.W., Mitter C., Denno R.F. \& Wilson M.R. 1994. Evolutionary patterns of host plant use by delphacid planthoppers and their relatives. In: Denno R.F. \& Perfect T.J. (eds) Planthoppers: Their Ecology and Management: 7-45. Chapman and Hall, New York.

https://doi.org/10.1007/978-1-4615-2395-6_2

Wilson S.W. 2005. Keys to the families of Fulgoromorpha with emphasis on planthoppers of potential economic importance in the southeastern United States (Hemiptera: Auchenorrhyncha). Florida Entomologist 88: 464-481. https://doi.org/10.1653/0015-4040(2005)88[464:KTTFOF]2.0.CO;2

Yang J.T. \& Yang C.T. 1986. Delphacidae of Taiwan (I) Asiracinae and the tribe Tropidocephalini (Homoptera: Fulgoroidea). Taiwan Museum Special Publication 6: 64-76.

Yang L., Chen X.S. \& Chen H.M. 1999. Notes on planthoppers infesting bamboo in Guizhou. Journal of Mountain Agriculture and Biology 18 (3): 154-161.

Yu F. \& Liang A.P. 2018. The Complete Mitochondrial Genome of Ugyops sp. (Hemiptera: Delphacidae). Journal of Insect Science 18 (3): 1-13. https://doi.org/10.1093/jisesa/iey063

Zhu K.Y. 1988. Description of a new species of Belocera from China (Homoptera: Delphacidae). Acta Zootaxonomica Sinica 13 (4): 397-399.

Manuscript received: 25 April 2019

Manuscript accepted: 18 November 2019

Published on: 6 May 2020

Topic editor: Gavin Broad

Desk editor: Eva-Maria Levermann 
Printed versions of all papers are also deposited in the libraries of the institutes that are members of the EJT consortium: Muséum national d'histoire naturelle, Paris, France; Meise Botanic Garden, Belgium; Royal Museum for Central Africa, Tervuren, Belgium; Royal Belgian Institute of Natural Sciences, Brussels, Belgium; Natural History Museum of Denmark, Copenhagen, Denmark; Naturalis Biodiversity Center, Leiden, the Netherlands; Museo Nacional de Ciencias Naturales-CSIC, Madrid, Spain; Real Jardín Botánico de Madrid CSIC, Spain; Zoological Research Museum Alexander Koenig, Bonn, Germany; National Museum, Prague, Czech Republic. 